\title{
Children Born to Mothers with Rash During Zika Virus Epidemic in Brazil: First 18 Months of Life
}

Renata Artimos de Oliveira Vianna, ${ }^{1} \mathrm{MD}, \mathrm{MSc}$, Kathryn Lynn Lovero, ${ }^{2}$ $\mathrm{PhD}$, Solange Artimos de Oliveira, ${ }^{1} \mathrm{MD}, \mathrm{PhD}$, Alexandre Ribeiro Fernandes, ${ }^{1} \mathrm{MD}, \mathrm{PhD}$, Teresa Cristina Sarmet dos Santos, ${ }^{1} \mathrm{MD}, \mathrm{MSc}$, Luiz Cláudio Santos de Souza Lima, ${ }^{1} \mathrm{MD}, \mathrm{PhD}$, Fabiana Rabe Carvalho, ${ }^{1} \mathrm{MSc}$, Maria Dolores Salgado Quintans, ${ }^{1} \mathrm{MD}$, MSc, Arnaldo Costa Bueno, ${ }^{1} \mathrm{MD}, \mathrm{PhD}$, Ana Flávia Malheiros Torbey, ${ }^{1} \mathrm{MD}, \mathrm{MSc}$, Aurea Lucia Alves Azevedo Grippa de Souza, ${ }^{1} \mathrm{MD}, \mathrm{MSc}$, Armanda de Oliveira Pache de Farias, ${ }^{1} \mathrm{MD}, \mathrm{MSc}$, Luiz Antonio Bastos Camacho, ${ }^{3} \mathrm{MD}$, DrPH, Lee Woodland Riley, ${ }^{4}$ $\mathrm{MD}$ and Claudete Aparecida Araújo Cardoso, ${ }^{1} \mathrm{MD}, \mathrm{PhD}$

${ }^{1}$ Faculdade de Medicina, Universidade Federal Fluminense, RJ 24.033-900, Brazil

${ }^{2}$ Department of Psychiatry, University of Columbia, New York 10032, USA

${ }^{3}$ Departamento de Epidemiologia e Métodos Quantitativos em Saúde, Fundação Oswaldo Cruz, Rio de Janeiro, RJ 21.041-210, Brazil ${ }^{4}$ Division of Infectious Diseases and Vaccinology, University of California, Berkeley 94720, USA

Renata Artimos de Oliveira Vianna and Kathryn Lynn Lovero contributed equally to this work.

Correspondence: Claudete Aparecida Araújo Cardoso, Faculdade de Medicina, Universidade Federal Fluminense, Rua Marquês de Paraná, 303, Centro, Niterói, Rio de Janeiro 24.033-900, Brazil. Tel: +55 21 3674-7282. E-mail < claudetecardoso@id.uff.br>.

\begin{abstract}
Objective: To better understand the clinical spectrum and course of congenital Zika syndrome (CZS) during the first 18 months of life of children whose mothers had rash during pregnancy.

Methods: This longitudinal observational study evaluated the clinical progress from birth until 18 months of life of children of mothers who developed rash during or up to 3 months before gestation. Maternal rash occurred from November 2015 to May 2017. The study subjects were divided into three groups: children whose mothers tested positive by RT-qPCR for Zika virus (ZIKV) (Group 1), children whose mothers tested negative by RT-qPCR for ZIKV (Group 2), and children whose mothers did not undergo any testing for ZIKV (Group 3) but tested negative for other congenital infections.
\end{abstract}


Results: Between April 2016 and July 2018, we studied 108 children: 43 in Group 1, 26 in Group 2 and 39 in Group 3. The majority of children were admitted into the study within 6 months of life. CZS was diagnosed in 26 children, equally distributed in Groups 1 and 3. Of 18 children with microcephaly, 6 were in Group 1 ( 1 postnatal) and 12 were in Group 3 (5 postnatal). Maternal rash frequency was 10 times higher during the first trimester than in the other trimesters (OR: 10.35; CI 95\%: 3.52-30.41). CZS was diagnosed during the follow-up period in 14 (54\%) cases. Developmental delays and motor abnormalities occurred in all children and persisted up to 18 months. Epilepsy occurred in 18 (69\%) of the cases.

Conclusions: Infants born of mothers exposed to ZIKV during pregnancy showed progression of developmental, motor and neurologic abnormalities even if they were born asymptomatic. Continued postnatal monitoring of such newborns is necessary to preclude disability-associated complications.

KEYWO RDS : Zika virus, Congenital Zika syndrome, microcephaly, RT-PCR

\section{INTRODUCTION}

Zika virus (ZIKV) infection, previously considered a mild febrile rash illness, took another form of clinical manifestation in Brazil that led the World Health Organization (WHO) to declare it a public health emergency of international concern in 2016 [1]. The epidemic of ZIKV infection at the beginning of 2015 and the increase in microcephaly notifications at the end of the same year in Brazil alerted health professionals to better understand the natural history of ZIKV infection. Over time, investigators have found that microcephaly is just one of a variety of neurological and developmental abnormalities associated with in utero ZIKV infection, mainly in the first or early second trimester, collectively referred to as congenital Zika syndrome (CZS) [2-4]. Based on this evidence, the Brazilian Ministry of Health $(\mathrm{BMoH})$ proposed a protocol for diagnosing ZIKV infection, emphasizing not only microcephaly, but other neurological manifestations to monitor potential risk factors for adverse child development during the follow-up period [5].

In April 2016, the Hospital Universitário Antônio Pedro at Universidade Federal Fluminense (HUAP/ UFF) began receiving suspected cases of congenital ZIKV infection, along with reports from other regions of Brazil [2, 3, 6-9]. Here, we describe and compare clinical manifestations during the first 18 months of life of 108 children whose mothers had rash during pregnancy.

\section{METHODS}

\section{Study design and participants}

A longitudinal, observational study was carried out on children whose mothers reported developing rash during pregnancy coinciding with the period of ZIKV Public Health Emergency of National Concern in Brazil (from November, 2015 to May, 2017) [10]. Children born to mothers with rash during pregnancy were referred from Health Units to the pediatric outpatient clinic of the HUAP/UFF, a reference center for suspected ZIKV infection cases in the Niterói area, a city in the Rio de Janeiro metropolitan area with approximately 500000 inhabitants. Children were admitted into the study through July 2018.

Laboratory evidence for ZIKV infection during pregnancy was based on mother's positive RT-qPCR test results on serum and/or urine samples, done during the $\mathrm{BMoH}$ recommended period at the flavivirus reference laboratory of Rio de Janeiro State (LACEN, RJ, Brazil), based on Lanciotti et al. [11]. A RT-qPCR positive test result at any point after maternal rash onset confirmed ZIKV infection; a negative test result excluded ZIKV infection if the blood sample was tested within the first five days of rash and/or the urine sample was tested by the 14th day [5]. Children were classified to belong to a 'suspected group', if no laboratory confirmation of ZIKV infection was made but if they tested negative for other congenital infections [5]. Maternal clinical records were used to assess prenatal syphilis, toxoplasmosis, rubella, cytomegalovirus and HIV infection. Serological screening for syphilis, toxoplasmosis, rubella, cytomegalovirus and HIV infection was done by the Liaison $\mathrm{XL}^{\circledR}$ equipment as part of routine procedures in the neonatal care clinic or, if lacking neonatal care, was conducted at their first visit to our clinic (Diasorin, Saluggia, Italia). Children with perinatal asphyxia, other etiology of 
microcephaly or other congenital infectious diseases were excluded from this study, as their outcomes may be similar to those associated with ZIKV exposure in utero.

After a written consent form was signed by children's legal guardian, the participants were classified into three groups:

a. Group 1: children whose mothers tested positive for ZIKV by RT-qPCR;

b. Group 2: children whose mothers tested negative for ZIKV by RT-qPCR;

c. Group 3: children whose mothers did not receive any laboratory testing for ZIKV.

CZS clinical diagnosis was based on the standard definition proposed by $\mathrm{BMoH}$ [5]. Briefly, suspected CZS was defined by the presence of neuroanatomical or neurosensory abnormalities, associated with maternal rash during pregnancy.

Head circumference (HC) data, obtained within 24-48 hours of birth, were collected from maternity hospital records. Microcephaly at birth was defined as $\mathrm{HC}$ more than two standard deviations (SD) below the mean for sex and gestational age and severe microcephaly as $\mathrm{HC}$ more than three $\mathrm{SD}$ [5]. $\mathrm{HC}$ was re-measured with a non-stretch Teflon tape at each visit. Head growth analyses were based on intergrowth fetal growth standards and the WHO child growth standards for infants $[12,13]$.

\section{Clinical evaluations}

After their admission, children were evaluated by a pediatrician, pediatric neurologist, ophthalmologist, otolaryngologist, orthopedist and speech therapist. The frequency of the evaluations depended on a child's disease severity, but usually were trimestral. WHO growth indicators were used to evaluate weight gain in children [12]. Denver Developmental Screening Test II (DDST-II) was used to evaluate development: language, psychosocial, gross motor and fine/adaptive motor skills [14]. Neurological abnormalities were classified into three stages: (a) mild, when a child had delays based on DDST-II; (b) moderate, when a child had DDST-II delays and motor abnormalities, such as hypertonia or hypotonia, spasticity, dysphagia, dyskinesia or dystonia; and (c) severe, when a child had (a) and (b) plus epilepsy, based on classification of the International League Against Epilepsy [15]. Neurological examination was done every 6 months or earlier, depending on disease severity.

Children underwent at least one neuroimaging test, including cranial ultrasound (CUS), computer tomography (CT) or magnetic resonance (MR). CUS was completed in infants less than 6 months of age; CT scans were done in children referred after 6 months, those who showed alterations in CUS, and those with a severe neurological damage. MR was done to clarify CUS and CT images. Auditory brainstem response (ABR), echocardiogram, and hip radiography were completed to assess auditory, heart, and joint development, respectively. Electroencephalogram was conducted on children with seizures.

\section{Statistical analysis}

Results were expressed as mean and standard deviation for continuous variables. Categorical variables were expressed as frequencies and compared by chisquared test, where $p<0.05$ was considered significant. Odds ratios and $95 \%$ confidence intervals (CI) were calculated to estimate the association of categorical variables among the study groups. Analyses were performed with Epi Info 2015 version 7.1.5.2 (Centers for Diseases Control and Prevention, Atlanta, Georgia, USA).

The study was approved by the ethics committee of the UFF.

\section{RESULTS}

During the study period, 114 children were referred to our hospital (Fig. 1). Six were excluded: two with perinatal asphyxia, two with congenital syphilis, one with listeriosis and one with primary microcephaly. The remaining 108 children were classified into three groups: 43 (40\%) whose mother had laboratory-confirmed ZIKV infection (Group 1), 26 (24\%) whose mother was excluded for ZIKV infection (Group 2), and 39 (36\%) whose mother was suspected to have been infected with ZIKV without a laboratory test (Group 3).

Overall, most mothers were less than 30 years old and had at least 9 years of schooling. Thirty-seven 


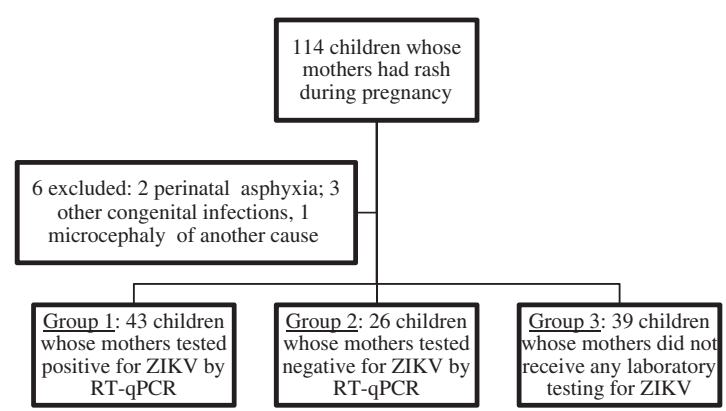

FIG. 1. Flowchart of study population.

ZIKV, Zika virus; RT-qPCR, real-time reverse transcription polymerase chain reaction.

percent of families earned one or less Brazilian monthly minimum wage, and $54 \%$ were residents of informal human settlements designated by the Brazilian Institute of Geography and Statistics as aglomerados subnormais (AGSN) [16], which were more frequent in Groups 1 and 2 compared to Group $3(p=0.008)$ (Table 1$)$.

The highest frequency of maternal rash (96\%) occurred from November 2015 to May 2016 (Fig. 2). Rash was reported in 31 (29\%) of mothers during the first trimester, compared to 49 (45\%) in the second trimester, $22(20 \%)$ in the third trimester and six $(5.5 \%)$ before pregnancy $(p=0.015)$. The highest frequency of rash in the first trimester of pregnancy occurred among mothers without a laboratory confirmation (46\%). Other maternal symptoms of ZIKV infection were similar across groups (Table 1).

\section{Clinical characteristics of children during the first year of life}

The majority $(70 \%)$ of children were recruited before 6 months of age. Median age (in months) at inclusion was $5(\mathrm{IQR}=1-8), 4(\mathrm{IQR}=0-7)$ and 1 $(\mathrm{IQR}=0-5)$, in Groups 1, 2 and 3, respectively. Ninety-two percent of the infants were born term.

Twenty-six (24\%) of 108 children were diagnosed with CZS; 13 in Group 1 and 13 in Group 3. Group 2 (RT-qPCR negative mothers) did not have CZS newborns. Nineteen (73\%) of 26 CZS children were male whereas among non CZS 15\% were female (OR: 15.8; CI 95\%: 4.9-53.2). Eighteen (58\%) of the CZS cases occurred among children of 31 mothers who developed rash in the first trimester compared to $8(10 \%)$ in those whose mother developed rash later (OR: 11.9; CI 95\%: 3.9-38.0). CZS was diagnosed at birth in 12 children (46\%) and 14 (54\%) children were diagnosed during the follow-up period until 10 months of life (Table 2).

Eighteen (69\%) CZS children had microcephaly: six $(33 \%)$ in Group 1 and $12(67 \%)$ in Group 3. The other eight children did not have microcephaly, but all had abnormalities related to CZS. Sixteen (15\%) infants had microcephaly diagnosed at birth (Table 2) and 12 of them had severe microcephaly. During the follow-up, four infants' HC normalized: three in Group 1 and one in Group 2. None of the children whose HC normalized had other neurologic, radiologic or anatomical abnormalities. Five children in Group 3 and one in Group 1 developed postnatal microcephaly, all with CZS. All HC reclassifications occurred before 10 months of life. At 1 year of follow-up, 12 of the 18 microcephaly confirmed cases were diagnosed at birth and the other six after birth (Table 2).

All CZS children had motor abnormalities and developmental delays. Epilepsy was diagnosed in 16 (61.5\%) CZS children with mean onset of 4.4 months (range: $0-10$ months). By neurological classification, 11 (42\%) CZS children were considered moderate and 15 (58\%) severe. Twenty-four (92\%) CZS children had dysphagia, three of them needed gastrostomy tube and seven had low weight for age. Ophthalmologic abnormalities (optic nerve hypoplasia, macular scarring, pigmentary retinal mottling or coloboma) were observed in $12 \mathrm{CZS}$ children. Eleven CZS children had clubfoot, eight had arthogryposis and two congenital hip dysplasia (Table 2).

At 12 months, seven (8.5\%) of 82 children with no CZS had isolated abnormalities by physical examination that did not fulfill the criteria for CZS (Table 2).

\section{Follow-up until 18 months of age}

By 18 months, 91 (84\%) of 108 children were evaluated. All CZS children persisted with different levels of developmental delays and motor abnormalities. Two new diagnosis of epilepsy were made in 
TABLE 1. Maternal sociodemographic and clinical characteristics of the study population

\begin{tabular}{|c|c|c|c|c|c|}
\hline Characteristics & $\begin{array}{c}\text { Group } 1 \\
(n=43) \\
n .(\%)\end{array}$ & $\begin{array}{c}\text { Group } 2 \\
(n=26) \\
n .(\%)\end{array}$ & $\begin{array}{c}\text { Group } 3 \\
(n=39) \\
n .(\%)\end{array}$ & $\begin{array}{c}\text { Total } \\
(n=108) \\
n .(\%)\end{array}$ & $p$ value $^{\mathrm{a}}$ \\
\hline Age group (years) & & & & & 0.406 \\
\hline$<30$ & $26(61)$ & $17(65)$ & $29(74)$ & $72(67)$ & \\
\hline$\geq 30$ & $17(39)$ & $9(35)$ & $10(26)$ & $36(33)$ & \\
\hline Mean $\left(\right.$ years) ${ }^{b}$ & $27.7(19-40)$ & $25.7(17-40)$ & $25.9(15-43)$ & 26.7 & \\
\hline Education (years) & & & & & 0.642 \\
\hline$\leq 9$ years & $15(35)$ & $12(46)$ & $16(41)$ & $43(40)$ & \\
\hline$>9$ years & $26(61)$ & $13(50)$ & $21(54)$ & $60(56)$ & \\
\hline Unknown & $2(4)$ & $1(4)$ & $2(5)$ & $5(4)$ & \\
\hline Household monthly income & & & & & 0.286 \\
\hline$\leq 1 \mathrm{MMW}^{\mathrm{c}}$ & $14(33)$ & $9(35)$ & $17(44)$ & $40(37)$ & \\
\hline$>1 \mathrm{MMW}^{\mathrm{c}}$ & $26(60)$ & $14(54)$ & $15(38)$ & $55(51)$ & \\
\hline Unknown & $3(7)$ & $3(11)$ & $7(18)$ & $13(12)$ & \\
\hline AGSN residence $^{\mathrm{d}}$ & & & & & 0.008 \\
\hline Yes & $28(65)$ & $17(65)$ & $13(33)$ & $58(54)$ & \\
\hline No & $12(28)$ & $8(31)$ & $22(56)$ & $42(39)$ & \\
\hline Unknown & $3(7)$ & $1(4)$ & $4(10)$ & $8(7)$ & \\
\hline Smoking & $4(9)$ & $7(27)$ & $6(15)$ & $17(16)$ & 0.150 \\
\hline Alcohol & $3(7)$ & $5(19)$ & $8(21)$ & $16(15)$ & 0.174 \\
\hline Rash & & & & & $0.015^{\mathrm{e}}$ \\
\hline Before pregnancy & $2(4)$ & 0 & $4(10)$ & $6(6)$ & \\
\hline 1st trimester & $10(23)$ & $3(11)$ & $18(46)$ & $31(29)$ & \\
\hline 2nd trimester & $22(52)$ & $15(58)$ & $12(31)$ & $49(45)$ & \\
\hline 3rd trimester & $9(21)$ & $8(31)$ & $5(13)$ & $22(20)$ & \\
\hline Fever & $14(32)$ & $11(42)$ & $18(46)$ & $43(40)$ & 0.435 \\
\hline Myalgia & $12(28)$ & $10(39)$ & $15(38)$ & $37(34)$ & 0.527 \\
\hline Arthralgia & $25(58)$ & $13(50)$ & $21(54)$ & $59(55)$ & 0.799 \\
\hline Headache & $8(19)$ & $7(27)$ & $11(28)$ & $26(24)$ & 0.553 \\
\hline Conjunctival hyperemia & $10(23)$ & $8(31)$ & $5(13)$ & $23(21)$ & 0.206 \\
\hline
\end{tabular}

${ }^{a}$ Pearson Chi-square test.

${ }^{\mathrm{b}}$ Mean range.

${ }^{c} \mathrm{MMW}=$ monthly minimum wage; $1 \mathrm{MMW}$ in Brazil is BRL $\$ 880.00$, the equivalent of USD $\$ 361.26$ (based on average USD-BRL exchange rate during the enrollment period of 2016).

${ }^{\mathrm{d}}$ AGSN = aglomerados subnormais (informal settlements defined by Brazilian Institute of Geography and Statistics).

${ }^{\mathrm{e}} 1$ st trimester versus other trimesters.

CZS children at 16 and 18 months, totaling 18 cases of epilepsy. Of 26 CZS children, 18 had microcephaly; 15 of them had severe neurological findings and three had moderate manifestations. Two of eight CZS children without microcephaly had severe neurological signs and the other six had moderate findings. Epilepsy was more frequently seen in children with microcephaly (OR: 15; CI 95\%: $1.98-$ 113.16). Dysphagia and ophthalmological abnormalities remained unchanged. Two more children with CZS developed low weight for age, totaling nine (35\%), all with dysphagia. Two of eight arthrogryposis cases showed clinical improvements after physiotherapy sessions (Table 3). 


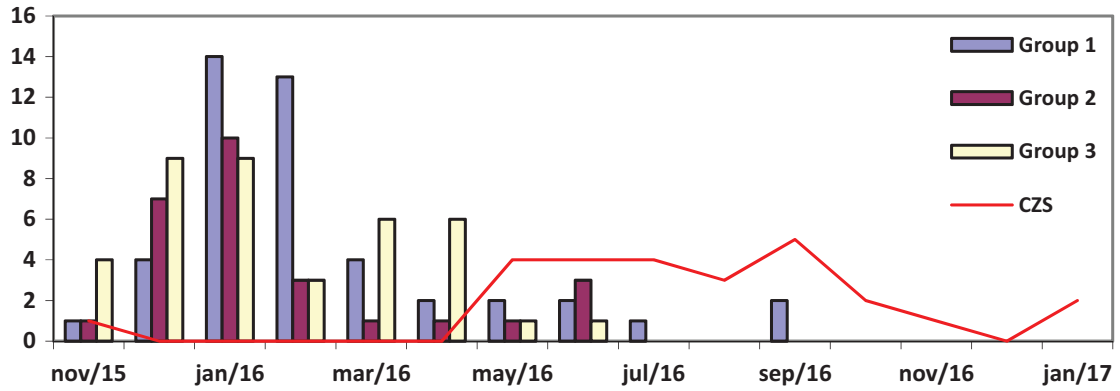

FIG. 2. Frequency of maternal rash by year and month, and CZS patients' month of birth.

CZS, congenital Zika syndrome.

None of 65 children without CZS at 12 months were diagnosed with CZS at 18 months (Table 3). Eleven of them had isolated abnormalities by physical examination that did not fulfill the criteria for CZS (Table 3). The mean of frequency of evaluations was 5 (range: $2-10$ ), with no differences between groups 1,2 and $3(p=0.400)$.

\section{Complementary tests}

Four of 87 ABR examinations showed abnormalities, two of them in CZS children with neurosensorial hearing loss. All 70 echocardiograms were normal, but one CZS child had an interatrial communication.

All children completed at least one neuroimaging test. The most common CT findings in CZS children were: calcifications (77\%), predominantly in the transitional area between the cortex and the white matter; cerebral cortex thinning (73\%), abnormalities of sulci and/or gyri (69\%); and ventriculomegaly (61.5\%). Seven (8.5\%) of 82 children without CZS had some neuroimaging findings, but all of them were asymptomatic. All MRI done in children without CZS were normal (Table 4).

All included children had negative screening test results for syphilis, toxoplasmosis, rubella, cytomegalovirus and HIV infection.

\section{DISCUSSION}

In our study 26 (24\%) of 108 children born of mothers with rash during pregnancy were diagnosed with CZS, 69\% of whom had microcephaly. We found 12 children diagnosed to have microcephaly at birth and another six developed postnatal microcephaly, emphasizing that children whose mother had rash during pregnancy with confirmed or suspected exposure to ZIKV in utero need to be monitored beyond birth even if they initially do not present with microcephaly. We should also emphasize that $54 \%$ of CZS cases were diagnosed during the first year of life. Van der Linden et al. [7] reported that 11 of 13 infants with laboratory evidence of CZS and normal $\mathrm{HC}$ at birth developed postnatal microcephaly during the first year of life. Eight CZS children without microcephaly had other clinical and neuroimaging abnormalities, findings also described by other authors $[3,17]$.

Figure 2 shows that the timing of study cases is consistent with the Zika epidemic period in Brazil, with the incidence of gestational rash reaching a maximum during the rainy season (November 2015-March 2016), followed by a wave of CZV diagnoses a few months later. The rash epidemic correlated more clearly with the distribution of RTqPCR-positive mothers, but negative and untested mothers were also identified during the same period. The cluster of RT-qPCR-negative mothers without CZS newborns may have resulted from heightened alert to gestational rash during the ZIKV epidemic in Brazil. During this period, the positive predictive value of rash for CZS was $24 \%$ at our study site.

Mothers in Group 3 were younger, less educated, had lower income, had more smokers and alcohol users, but differences were not significant except for the lower proportion of residents living in AGSN. Unfavorable sociodemographic conditions might partly explain why women in Group 3 did not 
TABLE 2. Clinical features up to 12 months of children of mothers who developed rash during pregnancy

\begin{tabular}{|c|c|c|c|c|}
\hline Clinical features & $\begin{array}{l}\text { Group 1 } \\
\text { RT-qPCR+ } \\
n=43\end{array}$ & $\begin{array}{l}\text { Group } 2 \\
\text { RT-qPCR- } \\
n=26\end{array}$ & $\begin{array}{l}\text { Group } 3 \\
\text { No RT-qPCR } \\
n=39\end{array}$ & $\begin{array}{l}\text { Total } \\
n=108\end{array}$ \\
\hline & no. (\%) & no. (\%) & no. $(\%)$ & no. (\%) \\
\hline Small for gestational age & $5(12)$ & $5(19)$ & $4(10)$ & $14(13)$ \\
\hline $\mathrm{CZS}$ & $13(30)$ & 0 & $13(33)$ & $26(24)$ \\
\hline Time of diagnosis of CZS & $(n=13)$ & $(n=0)$ & $(n=13)$ & $(n=26)$ \\
\hline At birth & $5(38)$ & 0 & $7(54)$ & $12(46)$ \\
\hline Up to 10 months of life & $8(62)$ & 0 & $6(46)$ & $14(54)$ \\
\hline Microcephaly & $6(14)$ & 0 & $12(31)$ & $18(16)$ \\
\hline \multicolumn{5}{|l|}{ Time of diagnosis of microcephaly } \\
\hline At birth ${ }^{\mathrm{a}}$ & $8(19)$ & $1(4)$ & $7(18)$ & $16(15)$ \\
\hline After birth & $1(3)$ & 0 & $5(13)$ & $6(6)$ \\
\hline Neurological findings ${ }^{\mathrm{b}}$ & $(n=43)$ & $(n=25)$ & $(n=38)$ & $(n=106)$ \\
\hline Normal & $27(62)$ & $24(96)$ & $22(58)$ & $73(69)$ \\
\hline Mild & $1(3)$ & $1(4)$ & 0 & $2(2)$ \\
\hline Moderate & $10(23)$ & 0 & $6(16)$ & $16(15)$ \\
\hline Severe & $5(12)$ & 0 & $10(26)$ & $15(14)$ \\
\hline Ophthalmologic examination & $(n=38)$ & $(n=25)$ & $(n=34)$ & $(n=97)$ \\
\hline Optic nerve abnormalities ${ }^{c}$ & $5(13)$ & 0 & $4(12)$ & $9(9)$ \\
\hline Choriorretinal abnormalities $^{c}$ & $5(13)$ & 0 & $6(18)$ & $11(11)$ \\
\hline \multicolumn{5}{|l|}{ Orthopedic examination } \\
\hline Arthrogryposis $^{\mathrm{d}}$ & $1(3)$ & 0 & $7(18)$ & $8(7)$ \\
\hline Clubfoot & $4(9)$ & $1(4)$ & $7(18)$ & $12(11)$ \\
\hline Congenital hip dysplasia & $1(3)$ & 0 & $1(3)$ & $2(2)$ \\
\hline Dysphagia $^{\mathrm{e}}$ & $13(30)$ & 0 & $14(37)$ & $27(25)$ \\
\hline Low weight for age $\mathrm{f}^{\mathrm{f}}$ & $6(14)$ & 0 & $4(10)$ & $10(9)$ \\
\hline Time of maternal rash / CZS children & $(n=13)$ & $(n=0)$ & $(n=13)$ & \\
\hline before pregnancy ${ }^{\mathrm{g}}$ & $1(8)$ & 0 & 0 & $1(4)$ \\
\hline $1^{\text {st }}$ trimester & $7(54)$ & 0 & $11(84)$ & $18(69)$ \\
\hline $2^{\text {nd }}$ trimester & $4(30)$ & 0 & $1(8)$ & $5(19)$ \\
\hline $3^{\text {rd }}$ trimester & $1(8)$ & 0 & $1(8)$ & $2(8)$ \\
\hline
\end{tabular}

${ }^{\mathrm{a}} \mathrm{HC}$ of three children in Group 1 and one in Group 2 normalized during the follow-up period.

${ }^{\mathrm{b}}$ Eight CZS children in Group 1 and three in Group 3 had moderate neurological findings. All severe neurological findings were observed in CZS children.

${ }^{c}$ Observed in 12 CZS children.

${ }^{\mathrm{d} O n l y}$ seen in CZS children.

e Observed in 11 CZS children of Group 1 and 13 of Group 3.

${ }^{\mathrm{f}}$ Seven CZS children had low weight for age ( $<-2 z$ score; WHO, 2016).

${ }^{\mathrm{g}} \mathrm{Up}$ to 3 months before pregnancy.

$\mathrm{CZS}$, congenital Zika syndrome; RT-qPCR, reverse transcription polymerase chain reaction.

undergo laboratory testing for ZIKV. Moreover, they might have not been aware of the pregnancy, especially in the first trimester, did not have medical request for test, did not seek medical care during the rash period or attributed the rash to allergy [18]. Among children of mothers who tested positive or were suspected to have been exposed to ZIKV in utero (presence of rash during pregnancy), 10 (38\%) 
TABLE 3. Clinical features of the study population by 18 months

\begin{tabular}{|c|c|c|c|c|c|c|c|}
\hline \multirow[t]{3}{*}{ Clinical features (CZS) } & \multicolumn{2}{|c|}{ Group 1} & \multirow{2}{*}{$\begin{array}{l}\text { Group } 2 \\
n=20\end{array}$} & \multicolumn{2}{|c|}{ Group 3} & \multicolumn{2}{|c|}{ Total } \\
\hline & \multicolumn{2}{|c|}{$n=39$} & & \multicolumn{2}{|c|}{$n=32$} & \multicolumn{2}{|c|}{$n=91$} \\
\hline & $\begin{array}{c}\text { CZS } \\
n=13(\%)\end{array}$ & $\begin{array}{c}\text { No CZS } \\
n=26(\%)\end{array}$ & $\begin{array}{c}\text { No CZS } \\
n=20(\%)\end{array}$ & $\begin{array}{c}\text { CZS } \\
n=13(\%)\end{array}$ & $\begin{array}{c}\text { No CZS } \\
n=19(\%)\end{array}$ & $\begin{array}{c}\text { CZS } \\
n=26(\%)\end{array}$ & $\begin{array}{c}\text { No CZS } \\
n=65(\%)\end{array}$ \\
\hline Low weight for age $\mathrm{a}^{\mathrm{a}}$ & $4(31)$ & $1(4)$ & 0 & $5(38)$ & $1(5)$ & $9(35)$ & $2(3)$ \\
\hline \multicolumn{8}{|c|}{ Neurological Examination } \\
\hline Normal & 0 & $22(85)$ & $16(80)$ & 0 & $16(84)$ & 0 & $54(83)$ \\
\hline Mild & 0 & $4(15)$ & $3(15)$ & 0 & $1(5)$ & 0 & $8(12)$ \\
\hline Moderate & $6(46)$ & 0 & $1(5)$ & $2(15)$ & $2(10)$ & $8(31)$ & $3(5)$ \\
\hline Severe & $7(54)$ & 0 & 0 & $11(85)$ & 0 & $18(69)$ & 0 \\
\hline Dysphagia & $11(85)$ & $1(4)$ & 0 & 13 & 0 & $24(92)$ & $1(2)$ \\
\hline Arthrogryposis & $1(8)$ & 0 & 0 & $5(38)$ & 0 & $6(23)$ & 0 \\
\hline $\begin{array}{l}\text { Ophthalmological } \\
\text { abnormalities }\end{array}$ & $6(46)$ & 0 & 0 & $6(46)$ & 0 & $12(46)$ & 0 \\
\hline
\end{tabular}

${ }^{\mathrm{a}}$ Low weight for age $<-2 z$ score (WHO, 2006).

${ }^{\mathrm{b}}$ Total of 67 children

of 26 children with CZS and 31 (63\%) of 49 children without CZS were residents of AGSN.

A negative RT-qPCR test in a mother with rash done during the recommended period had $100 \%$ predictive value for the absence of CZS in the newborn. These results suggest that, during an epidemic of Zika, efforts need to be made to test with RT-qPCR all pregnant mothers with rash, especially during the first trimester. Otherwise, $67 \%$ of ZIKV exposed mothers did not have a child with CZS at 18 months of followup. Therefore, children with no CZS signs/symptoms or with nonspecific findings at birth of mothers with rash during pregnancy who tested positive by RTqPCR should be closely monitored after birth, because clinical abnormalities may appear later.

First trimester maternal rash history occurred in $69 \%$ of CZS cases, showing that early occurrence of maternal infection was associated with worst prognosis. In addition, severe neurological presentation and arthrogryposis were also associated with first trimester maternal rash. Meneses et al. [9] described maternal rash during first trimester in 54\% of 87 children with CZS. Hoen et al. [19] analyzed ZIKV outbreak in French Territories in the Americas and found that the risk of CZS was $6.9 \%, 1.2 \%$, and $0.9 \%$, when the infection occurred in the first, second and third trimester, respectively.
In this study, microcephaly was a determining factor for the severity of other neurological manifestations, significantly associated with the higher frequency of epilepsy. Epilepsy occurred in 69\% of the CZS children, corroborating other studies, which report similar frequency $[20,21]$. All CZS children persisted with developmental delay and motor abnormalities up to 18 months of age, demonstrating the devastating progressive effect on central nervous system. Alves et al. [22], in a study in Pernambuco, observed similar results with severe impairment of neuropsychomotor development of children with microcephaly and CZS during the second year of life, even with supportive therapies.

Ocular lesions occurred in $46 \%$ of CZS cases and remained unchanged during follow-up. Similar results were observed by Zin et al. [23]. These authors also described ocular abnormalities in children without CZS, which was not found in our study. High frequency (92\%) of persistent dysphagia, compromised weight gain and low weight for age were seen during the follow-up. Similar results were reported by França et al. [24] that observed an insufficient weight gain in CZS children with microcephaly by 20 months of age compared to children without CZS at the same age. 
TABLE 4. Neuroimaging findings of the study population ${ }^{a}$

\begin{tabular}{|c|c|c|c|c|c|c|c|}
\hline \multirow{2}{*}{$\begin{array}{l}\text { Neurimaging findings } \\
\text { CUS }\end{array}$} & \multicolumn{2}{|c|}{ Group 1} & \multirow{2}{*}{$\begin{array}{l}\text { Group } 2 \\
\begin{array}{c}\text { No CZS } \\
n=12 \\
n(\%)\end{array}\end{array}$} & \multicolumn{2}{|c|}{ Group 3} & \multicolumn{2}{|c|}{ Total } \\
\hline & $\begin{array}{c}\text { CZS } \\
n=9 \\
n(\%)\end{array}$ & $\begin{array}{c}\text { No CZS } \\
n=17 \\
n(\%)\end{array}$ & & $\begin{array}{c}\text { CZS } \\
n=9 \\
n(\%)\end{array}$ & $\begin{array}{l}\text { No CZS } \\
\begin{array}{c}n=14 \\
n(\%)\end{array}\end{array}$ & $\begin{aligned} & \text { CZS } \\
& n=18 n(\%)\end{aligned}$ & $\begin{array}{c}\text { No CZS } \\
n=43 \\
n(\%)\end{array}$ \\
\hline Cerebral cortex thinning & $2(22)$ & 0 & 0 & $4(44)$ & 0 & $6(33)$ & 0 \\
\hline Ventriculomegaly & $3(33)$ & 0 & 0 & $3(33)$ & 0 & $6(33)$ & 0 \\
\hline Calcifications & $1(11)$ & 0 & 0 & $4(44.4)$ & 0 & $5(28)$ & 0 \\
\hline Corpus callosum hypoplasia & $1(11)$ & 0 & 0 & 0 & $1(7.1)$ & $1(6)$ & $1(2)$ \\
\hline Subependymal cist & 0 & $1(5.9)$ & 0 & 0 & $1(7.1)$ & $1(6)$ & $2(5)$ \\
\hline Brain stem hypoplasia & 0 & 0 & 0 & 0 & 0 & 0 & 0 \\
\hline Cerebellar hypoplasia & 0 & 0 & 0 & 0 & 0 & 0 & 0 \\
\hline Normal & $5(56)$ & $16(94.1)$ & $12(100)$ & $3(33.3)$ & $12(85.7)$ & $8(44)$ & $40(93)$ \\
\hline CT & $\begin{array}{l}n=13 \\
n(\%)\end{array}$ & $\begin{array}{l}n=25 \\
n(\%)\end{array}$ & $\begin{array}{l}n=18 \\
n(\%)\end{array}$ & $\begin{array}{l}n=13 \\
n(\%)\end{array}$ & $\begin{array}{l}n=16 \\
n(\%)\end{array}$ & $\begin{array}{c}n=26 \\
n(\%)\end{array}$ & $\begin{array}{l}n=59 \\
n(\%)\end{array}$ \\
\hline Calcifications & $8(62)$ & $1(4)$ & $1(6)$ & $12(92)$ & $3(18.8)$ & $20(77)$ & $5(9)$ \\
\hline Cerebral córtex thinning & $8(62)$ & 0 & 0 & $11(85)$ & 0 & $19(73)$ & 0 \\
\hline Abnormalities of sulci or gyri & $7(54)$ & 0 & 0 & $11(85)$ & 0 & $18(69)$ & 0 \\
\hline Ventriculomegaly & $7(54)$ & 0 & 0 & $9(69)$ & 0 & $16(62)$ & 0 \\
\hline Corpus collosum hypoplasia & $3(23)$ & 0 & 0 & $4(31)$ & 0 & $7(27)$ & 0 \\
\hline Cerebellar hypoplasia & $2(15)$ & 0 & 0 & $2(15)$ & 0 & $4(15)$ & 0 \\
\hline Brain stem hypoplasia & 0 & 0 & 0 & $2(15)$ & 0 & $2(8)$ & 0 \\
\hline Normal & $3(23)$ & $24(96)$ & $17(94)$ & 0 & $13(81.2)$ & $3(12)$ & $54(92)$ \\
\hline MRI & $\begin{array}{l}n=11 \\
n(\%)\end{array}$ & $\begin{array}{l}n=17 \\
n(\%)\end{array}$ & $\begin{array}{l}n=2 \\
n(\%)\end{array}$ & $\begin{array}{l}n=13 \\
n(\%)\end{array}$ & $\begin{array}{l}n=6 \\
n(\%)\end{array}$ & $\begin{array}{c}n=24 \\
n(\%)\end{array}$ & $\begin{array}{l}n=25 \\
n(\%)\end{array}$ \\
\hline Cerebral córtex thinning & $6(55)$ & 0 & 0 & $12(92)$ & 0 & $18(75)$ & 0 \\
\hline Ventriculomegaly & $6(55)$ & 0 & 0 & $12(92)$ & 0 & $18(75)$ & 0 \\
\hline Abnormalities of sulci or gyri & $6(55)$ & 0 & 0 & $12(92)$ & 0 & $18(75)$ & 0 \\
\hline Cranial facial disproportion & $5(46)$ & 0 & 0 & $11(85)$ & 0 & $16(67)$ & 0 \\
\hline Calcifications & $5(46)$ & 0 & 0 & $10(77)$ & 0 & $15(63)$ & 0 \\
\hline Corpus callosum hypoplasia & $6(55)$ & 0 & 0 & $9(69)$ & 0 & $15(63)$ & 0 \\
\hline Brain stem hypoplasia & $2(18)$ & 0 & 0 & $7(54)$ & 0 & $9(38)$ & 0 \\
\hline Cerebellar hypoplasia & $3(27)$ & 0 & 0 & $4(31)$ & 0 & $7(29)$ & 0 \\
\hline Other & $2(18)$ & 0 & 0 & 0 & 0 & $2(4)$ & 0 \\
\hline Normal & 0 & $17(100)$ & $2(100)$ & $1(8)$ & $6(100)$ & $1(8)$ & $25(100)$ \\
\hline
\end{tabular}

${ }^{\text {a }}$ Some children had more than one neuroimaging test.

CUS, cranial ultrasound; CT, computed tomography; MRI, magnetic resonance imaging.

No new CZS cases were detected in Groups 1 and 3 during the follow-up at 18 months of life. Children without CZS did not have clinical features or neuroimaging abnormalities. However, as clinical spectrum and long-term impact of ZIKV infection are not totally understood, longitudinal studies are important, especially for children with early mild CZS manifestations. 
This study has limitations. Adherence to all examinations and appointments was made difficult by the low socioeconomic status of the majority of families involved. Additionally, as ZIKV infection is thought to be symptomatic in $27 \%-50 \%$ of cases [25], we were unable to evaluate all children exposed to ZIKV in utero, and thus we cannot draw conclusions on precise incidence of CZS outcomes associated with in utero ZIKV exposure. Information about maternal dengue fever or Chikungunya infection, which may have signs and symptoms similar to those of Zika and share the same vector and seasonal distribution, was not routinely collected in prenatal care; thus, we were unable to evaluate in utero exposure to other flaviviruses. In our study, pregnant mothers who were not tested by RT-qPCR and developed rash during the first trimester, were more likely to have children with CZS than those who were tested. The former group of mothers was identified only after their children were diagnosed with CZS and hence this observation is biased. Untested mothers who developed rash during the first trimester who did not give birth to a child with CZS would not have entered the study. Because children were seen at a referral center, there is likely a selection bias, with the more severely affected children being referred. Thus, these findings cannot be generalized to all children at risk for Zika exposure. Since the affected children in this study are still young (18 months of age), precise predictions about their future developmental and functional status cannot be made.

While Brazil has ended its state of Zika epidemic as a public health emergency in May of 2017 [10], the large number of children with CZS is only the beginning of another type of epidemic of major national concern. The CZS cumulative cases in Brazil are currently estimated as 3279 [26]. Transmission of ZIKV in the Americas may now have entered a low-endemic pattern, which means that RT-qPCR tests to detect ZIKV infection will have lower positive predictive value. Nevertheless, the test's negative predictive value should remain high and thus, concentrated efforts at increasing screening mothers, especially those with rash during pregnancy, should be made to monitor future occurrence of CZS in newborns. Recently developed ZIKV-specific serological tests may also play an important role in clinical investigation and surveillance [27].

Infants born of mothers who develop rash during pregnancy need to be monitored beyond birth even if they are born asymptomatic. Early identification of developmental, cognitive, neurologic and motor abnormalities facilitates intervention and supportive care that may slow disability progression or improve quality of life of these children and their families.

\section{ACKNOWLEDGEMENTS}

The authors thank children and their families that participated in the study, Laboratório Multiusuário de Apoio à Pesquisa em Nefrologia e Ciências Médicas/LAMAP, Unidade de Pesquisa Clínica/UPC, and Zika Collaborative Group/UFF.

\section{FUNDING}

This work was financed in part by the Coordenação de Aperfeiçoamento de Pessoal de Nível Superior (CAPES) Finance Code 001, and Fulbright Commission and Global Health Equity Scholars Program (Fogarty International Center, National Institutes of Health), grant number R25 TW009338.

Conflicts of Interest: The authors have no conflicts of interest relevant to this article to disclose.

\section{REFERENCES}

1. World Health Organization. WHO Director-General Summarizes the Outcome of the Emergency Committee Regarding Clusters of Microcephaly and Guillain-Barré syndrome. http://www.who.int/en/news-room/detail/ 01-02-2016-who-director-general-summarizes-the-out come-of-the-emergency-committee-regarding-clusters-ofmicrocephaly-and-guillain-barr\%C3\%A9-syndrome $\quad(26$ October 2018, date last accessed).

2. Araujo TVB, Rodrigues LC, Ximenes RAA, et al. Association between microcephaly, Zika virus infection, and other risk factors in Brazil: final report of a casecontrol study. Lancet Infect Dis 2018;18:328-36.

3. Brasil P, Pereira JP, Moreira ME, et al. Zika virus infection in pregnant women in Rio de Janeiro. N Engl J Med 2016;375:2321-34.

4. Moore CA, Staples JE, Dobyns WB, et al. Characterizing the pattern of anomalies in congenital Zika syndrome for pediatric clinicians. JAMA Pediatr 2017;171:288-95.

5. Brasil. Ministério da Saúde. Orientações Integradas de Vigilância e Atenção à Saúde no Âmbito da Emergência de Saúde Pública de Importância Nacional. http://porta larquivos.saude.gov.br/images/pdf/2016/dezembro/ 
12/orientacoes-integradas-vigilancia-atencao.pdf October 2018, date last accessed).

6. França GV, Schuler-Faccini L, Oliveira WK, et al. Congenital zika virus syndrome in Brazil: a case series of the first 1501 livebirths with complete investigation. Lancet 2016;388:891-7.

7. Van der Linden V, Pessoa A, Dobyns W, et al. Description of 13 infants born during October 2015 January 2016 with congenital Zika Infection without microcephaly at birth- Brazil, 2016. MMWR Morb Wkly Rep 2016;65:1-142.

8. Aragão M, Holanda AC, Brainer-Lima AM, et al. Nonmicrocephalic infants with congenital Zika syndrome suspected only after neuroimaging evaluation compared with those with microcephaly at birth and postnatally: how large is the Zika virus "Iceberg"? AJNR Am J Neuroradiol 2017;38:1427-34.

9. Meneses JDA, Ishigami AC, Mello LM, et al. Lessons learned at the epicenter of Brazil's congenital Zika epidemic: evidence from 87 confirmed cases. Clin Infect Dis 2017;64:1302-8.

10. Brasil 2017. Ministério da Saúde. Secretaria de Vigilância em Saúde. Ministério da Saúde declara fim da Emergência Nacional para Zika e Microcefalia. Publicado em 11 de maio de 2017. http://portalms. saude.gov.br/noticias/svs/28348-ministerio-da-saudedeclara-fim-da-emergencia-nacional-para-zika-e-microce falia (26 October 2018, date last accessed).

11. Lanciotti RS, Kosoy OL, Laven JJ, et al. Genetic and serologic properties of Zika vírus associated with an epidemic, Yap State, Micronesia, 2007. Emerg Infect Dis 2018;14:1232-9.

12. WHO Multicentre Growth Reference Study Group. WHO Child Growth standards based on length/height, weight and age. Acta Paediatr Suppl 2006;95:S76-85.

13. Villar J, Altman DG, Purwar M, et al. The objectives, design and implementation of the Intergrowth 21 st project. BJOG 2013;120:9-26.

14. Frankenburg WK, Dodds J, Archer P, et al. DENVER II: Training Manual. 2nd edn. Denver, USA: Denver Developmental Materials; 1992.

15. Fisher RS, Acevedo C, Arzimanoglou A, et al. A practical clinical definition of epilepsy. Epilepsia 2014;55:475-8.

16. IBGE. Instituto Brasileiro de Geografia e Estatística. Aglomerados Subnormais Informações Territoriais, 2010. https://ww2.ibge.gov.br/home/presidencia/noti cias/imprensa/ppts/ 00000015164811202013480105748802.pdf （February 2019, date last accessed).

17. Nogueira ML, Nery Junior NRR, Estofolete CF, et al. Adverse birth outcomes associated with Zika virus exposure during pregnancy in São José do Rio Preto, Brazil. Clin Microbiol Infect 2018;24:646-52.

18. Snyder RE, Boone CE, Cardoso CAA, et al. Zika: a scourge in urban slums. PLoS Negl Trop Dis 2017;11: e0005287.

19. Hoen B, Schaub B, Funk AL, et al. Pregnancy outcomes after ZIKV infection in French territories in the Americas. N Engl J Med 2018;378:985-94.

20. Van der Linden H, Carvalho MD, Van der Linden V, et al. Epilepsy profile in infants with congenital Zika virus infection. N Engl J Med 2018;379:891-2.

21. Pessoa A, Van der Linden V, Yeargin-Allsopp M, et al. Motor abnormalities and Epilepsy in infants and children with evidence of congenital Zika virus infection. Pediatrics 2018;141:S167.

22. Alves L, Paredes CE, Silva GC, et al. Neurodevelopment of 24 children born in Brazil with congenital Zika syndrome in 2015: a case series study. BMJ Open 2018;8: e021304.

23. Zin AA, Tsui I, Rossetto J, et al. Screening criteria for ophthalmic manifestations of congenital zika virus infection. JAMA Pediartr 2017;171:847-54.

24. França TLB, Medeiros WR, Souza NL, et al. Growth and development of children with microcephaly associated with congenital Zika virus syndrome in Brazil. Int J Environ Res Public Health 2018;15. pii:E1990.

25. Mitchell PK, Mier-Y-Teran-Romero L, Biggerstaff BJ, et al. Reassessing Serosurvey-Based Estimates of the Zika Symptomatic Proportion. Am J Epidemiol 2019; 188:206-213.

26. Brasil. Ministério da Saúde. Secretaria de Vigilância em Saúde. Boletim Epidemiológico 54. Monitoramento Integrado de Alterações no Crescimento e Desenvolvimento Relacionadas à Infecção pelo Vírus Zika e Outras Etiologias Infecciosas, até a Semana Epidemiológica 45 de 2018. http://portalarquivos2. saude.gov.br/images/pdf/2018/dezembro/14/2018061.pdf (February 2019, date last accessed).

27. Balmaseda A, Zambrana JV, Collado D, et al. Comparison of four serological methods and two reverse transcription-PCR assays for diagnosis and surveillance of Zika virus infection. J Clin Microbiol 2018;56: e01785-17. 